\title{
The effect of adherence to guidelines for initial antiretroviral therapy on 1-year outcomes: a French cohort study
}

Laurent Cotte ${ }^{1,2^{*}}$, Thomas Bénet ${ }^{3,4}$, Philippe Vanhems ${ }^{3,4}$, Corinne Brochier ${ }^{5}$, Thomas Perpoint ${ }^{1}$, Tristan Ferry $1,6,7$ and Christian Chidiac ${ }^{1,6}$

\begin{abstract}
Background: Guidelines for antiretroviral treatment (CART) are published regularly, but there is little information regarding the effect of adherence to guidelines on patient outcomes. We assessed the effect of following the "when-to-start" and "what-to-start" guidelines, on treatment modifications, and on immunological and virological outcome at 12 months in a cohort of HIV-1 infected patients initiating CART from 2000 to 2010.

Methods: Consecutive HIV-1 infected patients, antiretroviral naive, initiating CART from 2000 to 2010 at a University Hospital were enrolled. HIV-2 infection, CART for prevention of mother-to-child transmission or during primary HIV-infection and unlicensed drugs were excluded. The respect or not of the "when-to-start" and "what-to-start" guidelines was based on French guidelines published from 2000 to 2010. Factors associated with cART modifications at 12 months and factors associated with an HIV viral load of $<50$ copies $/ \mathrm{mL}$ at 12 months were assessed by univariate and multivariate logistic regression modeling. Variations in CD4 counts from baseline were assessed by univariate and multivariate linear regression.

Results: Of 1365 patients starting CART, 151 were treated outside "when-to-start" guidelines and 150 were treated outside "what-to-start" guidelines. Not using "when-to-start" guidelines was mainly related to early initiation in young men having sex with men, and was not associated with a significantly different outcome at 12 months. Treatments that did not follow "what-to-start" guidelines were not observed in any specific population and were associated with more treatment modifications and a poorer virological outcome at 12 months.

Conclusions: Adherence to "what-to-start" guidelines is associated with a better outcome at 12 months in HIV-infected patients initiating antiretroviral therapy. Efforts should be made to promote adherence to these guidelines.
\end{abstract}

Keywords: HIV infection, Antiretroviral treatment, Adherence to guidelines, Prognosis

\section{Background}

The introduction of combined antiretroviral therapy (cART) in 1996 led to a dramatic improvement in HIV disease prognosis, from a deadly disease to a manageable chronic infection compatible with a normal or nearnormal life expectancy [1-3]. Since then, several national or international scientific societies have published guidelines to help physicians decide the optimal time to start

\footnotetext{
* Correspondence: laurent.cotte@chu-lyon.fr

'Department of Infectious and Tropical Diseases, Hôpital de la Croix-Rousse, Hospices Civils de Lyon, Lyon, France

2INSERM, U1052, Lyon, France
}

Full list of author information is available at the end of the article antiretroviral treatment ("when-to-start" guidelines) and the optimal antiretroviral combinations to use ("what-to-start" guidelines) [4-7]. Guidelines are updated regularly based on availability of new drugs and evidence from clinical trials. Most national and international consensus guidelines are broadly similar in their recommendations, particularly around "what-to-start".

Following the guidelines depends on the availability of the drugs and the organization of the health-care system, but also on physicians' personal experience. For example, prescription of not recommended drugs may occur because of the guidelines lag behind clinical trial results but also in specific clinical situations such as HCV or

\section{Ciomed Central}

(c) 2014 Cotte et al.; licensee BioMed Central Ltd. This is an Open Access article distributed under the terms of the Creative Commons Attribution License (http://creativecommons.org/licenses/by/4.0), which permits unrestricted use, distribution, and reproduction in any medium, provided the original work is properly credited. The Creative Commons Public Domain Dedication waiver (http://creativecommons.org/publicdomain/zero/1.0/) applies to the data made available in this article, unless otherwise stated. 
HBV coinfections, renal insufficiency or treatment of opportunistic infections. The availability of numerous drugs facilitates the prescription of various combinations in industrialized countries, resulting in a significant proportion of prescriptions outside the recommendations [8].

Few studies have reported adherence to guidelines in industrialized countries [9-15]. Some of these studies included patients who started antiretroviral treatment before the cART era [10] or shortly after [11,12,14], a time when suboptimal treatments such as dual-nucleoside combinations were still prescribed. Most of these studies focused on adherence to guidelines and little information was available regarding the effect of adherence to guidelines on the outcome of cART [14].

We conducted an analysis of first line cART in a large cohort of patients who initiated cART from 2000 to 2010. We hypothesized that good adherence to guidelines would improve patients' outcome, independent of the time period. One-year outcomes were studied according to whether or not the patient's treatment followed the French national guidelines applicable during the time of treatment.

\section{Methods}

\section{Study population and design}

The Department of Infectious and Tropical Diseases at Croix-Rousse Hospital in Lyon, France, follows approximately 2,500 HIV-infected patients yearly. The Department provides care to patients from the diagnosis of HIV infection to complications from AIDS, leading to a high retention rate. This hospital cohort is included in the French Hospital Database on HIV and follows the protocols described elsewhere [16]. Patients' files are registered in a computerized database after the patient provides written informed consent. The database is registered by the French Commission Nationale de l'Informatique et des Libertés under the reference CNIL 1599796. The study was performed in accordance with The ICHGCP guidelines and the Declaration of Helsinki. Every treatment-naïve adult patient, initiating cART from January 2000 to December 2010, and for whom baseline and 12-month data were available (or deceased before month 12) were included. Patients with HIV-2 infection or who were initiating cART for the prevention of mother-to-child transmission only, those initiating cART during primary HIV infection, or who were using unapproved cART drugs in a clinical trial were excluded.

\section{Data collection}

Demographic and biological data at baseline and at 12 months were recorded. The time from HIV diagnosis to cART initiation was also recorded, as well as the duration of the first line of treatment and the reason for treatment modification or interruption if it occurred during the first year.

\section{Description of outcomes and risk factors}

The timing of cART initiation ("when-to-start" guidelines) was defined as "recommended", "optional", or "not recommended" on the basis of actual CD4 count, HIV viral load, and other specific conditions such as hepatitis $B$ virus $(\mathrm{HBV})$ or hepatitis $\mathrm{C}$ virus $(\mathrm{HCV})$ coinfection, high cardio-vascular risk, or treatment as prevention [17-22]. Since guidelines were not published at a defined date, 2-years intervals were considered for determining whether guidelines were followed (e.g. 2002 guideline was considered for treatment initiation from January 2002 to December 2003). These 2-years intervals were labeled by the year of publication of the guidelines. The period of time from 2000-2010 was retained for this study for homogeneity of cART, since dual-nucleosides combinations were no longer recommended and boosted protease inhibitors started to be widely used in France beginning in the year 2000. Recommended and optional cART were grouped together for analysis. Table 1a summarizes the French "when-to-start" guidelines from 2000 to 2010 .

The choice of antiretrovirals and the type of combination ("what-to-start" guidelines) was defined as "preferred", "alternative", or "not recommended". Since new drugs were often classified as "alternative" before being classified as "preferred", these 2 categories were grouped for analysis. Table 1b summarizes the French "what-tostart" guidelines.

cART modification was defined as any change of at least 1 antiretroviral during the first year of treatment. Dosage adjustments and switch to fixed-dose combinations using the same molecules were not considered modifications.

The main reason for treatment modification or interruption was classified at the time of event as virological failure (defined by a confirmed HIV-RNA > 200 copies/ $\mathrm{mL}$ at 6 months or $>50$ copies/mL at 12 months), toxicity/tolerance issues, simplification of treatment, patient request (including observance issues), and other reasons, including pregnancy and pharmacological interactions.

\section{Statistical analyses}

Qualitative variables were reported as numbers and percentages and were compared with the Chi2 test. Quantitative variables were reported as medians with interquartile range (IQR) and were compared with the Mann-Whitney $U$ Test. The Chi2 test for linear trends was used to assess the effect of the year of guideline publication on the outcomes.

Factors associated with cART modifications at 12 months and factors associated with an HIV viral load $<50$ cop$\mathrm{ies} / \mathrm{mL}$ at 12 months were assessed by univariate and 
Table 1 French guidelines for cART initiation from 2000 to 2010

\begin{tabular}{|c|c|c|c|c|c|c|}
\hline \multicolumn{7}{|c|}{ a "When-to-start" guidelines } \\
\hline & 2000 & 2002 & 2004 & 2006 & 2008 & 2010 \\
\hline $\mathrm{CDC} B-\mathrm{C}$ & Rec. & Rec. & Rec. & Rec. & Rec. & Rec. \\
\hline $\mathrm{CD} 4<200 / \mathrm{mm}^{3}$ & Rec. & Rec. & Rec. & Rec. & Rec. & Rec. \\
\hline CD4 < 15\% & Rec. & Rec. & Rec. & Rec. & Rec. & Rec. \\
\hline CD4 200-349/mm $\mathrm{mm}^{3}$ & Rec. & Opt. (1) & Rec. & Rec. & Rec. & Rec. \\
\hline CD4 350-500/mm $\mathrm{mm}^{3}$ & & NR & Opt. (1) & Opt. (1) & Opt. (2) & Rec. \\
\hline $\mathrm{CD} 4>500 / \mathrm{mm}^{3}$ & & NR & NR & NR & NR & Opt. (3) \\
\hline
\end{tabular}

b "What-to-start" guidelines

\begin{tabular}{|c|c|c|c|c|c|c|}
\hline & 2000 & 2002 & 2004 & 2006 & 2008 & 2010 \\
\hline \multicolumn{7}{|c|}{ NRTIs Backbone } \\
\hline ZDV + ddl & Pref. & Pref. & Alt. & Pref. & NR & NR \\
\hline ZDV +3TC & Pref. & Pref. & Pref. & Pref. & Alt. & Alt. \\
\hline$d 4 T+d d l$ & Pref. & $N R$ & NR & $N R$ & NR & $N R$ \\
\hline $\mathrm{d} 4 \mathrm{~T}+3 \mathrm{TC}$ & Pref. & Pref. & Alt. & $N R$ & $N R$ & NR \\
\hline ZDV + FTC & & Alt. & Pref. & Pref. & Alt. & Alt. \\
\hline TDF +3TC & & Alt. & Pref. & Pref. & Pref. & Alt. \\
\hline TDF + FTC & & Alt. & Pref. & Pref. & Pref. & Pref. \\
\hline $\mathrm{ddl}+3 \mathrm{TC}$ & & Alt. & Pref. & Pref. & Pref. & $N R$ \\
\hline $\mathrm{ddl}+\mathrm{FTC}$ & & Alt. & Pref. & Pref. & Pref. & NR \\
\hline$A B C+3 T C$ & & Alt. & Pref. & Pref. & Pref. & Pref. \\
\hline$A B C+F T C$ & & Alt. & Pref. & Pref. & Pref. & Alt. \\
\hline $\mathrm{ddl}+\mathrm{TDF}$ & & Alt. & Alt. & $N R$ & $N R$ & $N R$ \\
\hline
\end{tabular}

3 NRTIs combinations

$\mathrm{ABC}+3 \mathrm{TC}+\mathrm{dd}$

$A B C+3 T C+d 4 T$

ZDV $+3 T C+d d$

$\mathrm{ABC}+3 \mathrm{TC}+\mathrm{TDF}$

TDF $+\mathrm{ddl}+3 \mathrm{TC}$

$\mathrm{ZDV}+3 \mathrm{TC}+\mathrm{ABC}$

Other 3 NRTI

combinations

Unboosted Pls

\begin{tabular}{|c|c|c|c|c|c|c|}
\hline RTV & Pref. & $N R$ & $N R$ & $N R$ & $N R$ & NR \\
\hline IDV & Pref. & $N R$ & NR & NR & NR & $N R$ \\
\hline NFV & Pref. & Pref. & Alt. & $N R$ & & \\
\hline \multicolumn{7}{|c|}{ Boosted PIs } \\
\hline APVr & Alt. & Alt. & & & & \\
\hline SQVr & Pref. & Pref. & Pref. & Pref. & Alt. & Alt. \\
\hline IDVr & Alt. & Pref. & Pref. & Alt. & Alt. & Alt. \\
\hline LPVr & Alt. & Pref. & Pref. & Pref. & Pref. & Pref. \\
\hline fAPVr & & & Pref. & Pref. & Pref. & Alt. \\
\hline ATVr & & & & Alt. & Pref. & Pref. \\
\hline $\mathrm{DRV} r$ & & & & NR & Alt. & Pref. \\
\hline
\end{tabular}

NNRTIS
Table 1 French guidelines for CART initiation from 2000 to 2010 (Continued)

\begin{tabular}{|c|c|c|c|c|c|c|}
\hline EFV & Pref. & Pref. & Pref. & Pref. & Pref. & Pref. \\
\hline NVP & Pref. & Pref. & Pref. & Alt. & Alt. & Alt. \\
\hline \multicolumn{7}{|l|}{ Integrase Inhibitor } \\
\hline RAL & & & & & & Alt. \\
\hline \multicolumn{7}{|l|}{$\begin{array}{l}\text { Antiretroviral } \\
\text { combinations }\end{array}$} \\
\hline $\begin{array}{l}\text { NNRTI + PI (boosted } \\
\text { or not) }\end{array}$ & & & & NR & NR & NR \\
\hline 2 NRTIS +1 NNRTI & Pref. & Pref. & Pref. & Pref. & Pref. & Pref. \\
\hline 2 NRTIs + $1 \mathrm{Pl}$ & Pref. & Pref. & Alt. & NR & NR & NR \\
\hline 2 NRTIs + 1 boosted PI & Pref. & Pref. & Pref. & Pref. & Pref. & Pref. \\
\hline $\begin{array}{l}\text { Boosted PI } \\
\text { monotherapy }\end{array}$ & & & & NR & NR & NR \\
\hline
\end{tabular}

Abbreviations: Rec ART recommended, Opt ART optional, NR ART Not recommended; (1), if HIV-RNA $>10^{5} \log$ copies/ml; (2), if HIV-RNA $>10^{5} \log$ copies/ml $>50$ years, HBV/HCV coinfection or high cardiovascular risk; (3), if HIV-RNA $>10^{5}$ log copies $/ \mathrm{ml}$, $>50$ years, HBV/HCV coinfection, high cardiovascular risk or treatment as prevention.

Abbreviations: ZDV zidovudine, $d d l$ didanosine, 3TC lamivudine, $d 4 T$ stavudine, FTC emtricitabine, TDF tenofovir, $A B C$ abacavir, NRTI nucleoside/nucleotide reverse transcriptase inhibitors, $P /$ protease inhibitor, RTV ritonavir, IDV indinavir, NFV nelfinavir, APVr boosted amprenavir, SQVr boosted saquinavir, IDVr boosted indinavir, LPVr boosted lopinavir, fAPVr boosted fosamprenavir, ATVr boosted atazanavir, $D R V r$ boosted darunavir, NNRTI non-nucleoside reverse transcriptase inhibitors, EFV efavirenz, NVP nevirapine, RAL raltegravir, Pref preferred, Alt alternative, NR Not recommended; (1), if HIV-RNA $<10^{5} \log$ copies $/ \mathrm{ml}$.

multivariate logistic regression modeling. Variations in CD4 counts from baseline were assessed by univariate and multivariate linear regression.

The independent variables were whether the treatments followed the "when-to-start" and "what-to-start" guidelines. The following potential confounders were tested: year guidelines were published, age at cART initiation, risk factors for HIV infection, delay between HIV diagnosis and cART initiation, presence of $\mathrm{HBV} / \mathrm{HCV}$ coinfection, Centers for Disease Control and Prevention (CDC) stage, HIV viral load, and CD4 count at cART initiation.

After univariate analysis, independent variables and potential confounders were entered in multivariate models if their $P$ value was $\leq .15$; a backward stepwise process was then implemented and models were compared with the Wald test. Baseline CD4 count was forced in the predictive model of CD4 count variation at 12 months. Baseline HIV viral load was forced in the predictive model of undetectable HIV viral load at 12 month. All statistical tests were 2 -tailed, and $P<.05$ was considered statistically significant. The viral suppression rate at 12 months was analyzed in an intention to treat (ITT) way (i.e. that all switches were counted as failures). The data were analyzed by Stata software 11.0 (StataCorp LP 2009, College Station, TX). Missing data were avoided by complete case analysis. 


\section{Results}

From January 2000 to December 2010, 1365 patients initiated cART accordingly to the inclusion criteria. The demographics and clinical characteristics of the patients at baseline are summarized in Table 2 .

cART not following the current "when-to-start" guidelines was initiated in 151 patients (11\%). Treatment not following the guidelines declined from $22 \%$ in the 20002001 period to $6 \%$ in $2010(P<.001)$. Factors associated with not following the "when-to-start" guidelines at cART initiation included younger age, male gender, men having sex with men, CDC stage A-B, higher CD4 count, and lower HIV viral load at baseline.

One hundred and thirty-two different cART combinations were prescribed; 65 that followed the "what-tostart" guidelines and 67 that were outside the guidelines. These 67 regimens outside the guidelines represented 150 patients and included suboptimal combinations such as 2 or 3 nucleoside/nucleotide reverse transcriptase inhibitors (NRTI) (25 patients), more than 3 drugs $(n=69)$, 2 NRTI with a fusion inhibitor $(\mathrm{n}=10)$ and other combinations of 3 drugs from 3 different classes $(n=46)$. cART that followed the current "what-to-start" guidelines was initiated in 1215 patients (89\%) and treatments that were outside guidelines were initiated for 150 (11\%). Prescription of drugs outside the current guidelines declined from $18 \%$ in the $2000-2001$ period to $9 \%$ in $2010(P<.001)$. Factors associated with initiating cART that did not follow the "what-to-start" guidelines included older age, male gender, a shorter delay between HIV diagnosis and cART initiation, $\mathrm{CDC}$ stage $\mathrm{C}$, lower $\mathrm{CD} 4$ count, and higher HIV viral load at baseline. Factors associated with following or not following the guidelines are summarized in Table 2.

Eleven patients died during the first year of follow up. At 12 months, $64.3 \%$ of patients had an undetectable HIV-RNA $<50$ copies/mL, $31.9 \%$ had a CD4 count greater than $500 / \mathrm{mm}^{3}$, and $43.6 \%$ reported at least 1 treatment modification during the first year of treatment. The proportion of patients with HIV-RNA $<50$ copies/mL at 12 months increased from $46.7 \%$ for the 2000-2001 period to $73.1 \%$ for $2010(P<.001)$. Similarly, the proportion of patients with CD4 counts $>500 / \mathrm{mm}^{3}$ at 12 months increased from $28.6 \%$ to $43.2 \%(P<.001)$. Conversely, the proportion of patients reporting cART modification during the first year decreased from 52.1\% to $22.6 \%(P<.001)$. Reasons for cART modification were virological failure in $6.6 \%$ of patients $(\mathrm{n}=39)$, toxicity/ tolerance issue in $41.0 \%(\mathrm{n}=244)$, simplification in 21.3\% $(n=127)$, patient request in $7.9 \%(n=47)$, and other reasons in $23.2 \%(\mathrm{n}=138)$.

The proportion of patients with an HIV viral load $<50$ copies $/ \mathrm{mL}$ at 12 months was similar for patients initiating cART with treatments that followed and did not follow the "when-to-start" guidelines, as well as the proportion of patients with a treatment modification during the first year. The median CD4 count was higher at 12 months for patients initiating cART that did not follow the "when-tostart" guidelines $(P<.001)$, whereas the CD4 increase from baseline was lower in these patients $(P=.006)$.

Conversely, patients initiating cART with treatments that did not follow the "what-to-start" guidelines reported more treatment modifications $(P<.001)$, experienced undetectable HIV-RNA less frequently, and had lower CD4 counts and lower CD4 count increases at 12 months than patients initiating cART according to the guidelines $(P<.001)$. The 12 -month outcome data are summarized in Table 3.

After univariate regression analysis, treatments not following the "when-to-start" guidelines were associated with decreased CD4 counts (crude Regression Coefficient $[\mathrm{cRC}]=-39.5,95 \%$ CI $-66.4 ;-12.6, P=.004)$, but was not associated with treatment modification (crude odds ratio $[\mathrm{OR}]=0.95,95 \% \mathrm{CI} 0.67-1.33, P=.75$ ) or HIV-RNA $<50$ copies $/ \mathrm{mL}$ at 12 months $(\mathrm{cOR}=1.12$, 95\% CI 0.78-1.60, $P=.54$ ). Not following the "what-to-

Table 2 Demographic and baseline characteristics of patients receiving treatments that did/did not follow the guidelines

\begin{tabular}{|c|c|c|c|c|c|c|c|}
\hline \multirow[b]{2}{*}{ Characteristic } & \multirow{2}{*}{$\begin{array}{l}\text { All population } \\
\mathrm{N}=1,365\end{array}$} & \multicolumn{3}{|c|}{ Followed "when-to-start" guidelines } & \multicolumn{3}{|c|}{ Followed "what-to-start" guidelines } \\
\hline & & Yes $(n=1,214)$ & No $(n=151)$ & $\mathbf{P}$ & Yes $(n=1,215)$ & No $(n=150)$ & $\mathbf{P}$ \\
\hline Male (\%) & 69.7 & 68.6 & 78.2 & 0.02 & 68.7 & 77.3 & 0.03 \\
\hline Median Age (years) & 37.3 & 37.5 & 34.7 & 0.002 & 37.1 & 38.5 & - \\
\hline MSM (\%) & 41.4 & 39.0 & 60.9 & $<0.001$ & 41.1 & 44.0 & - \\
\hline HBV/HCV coinfection (\%) & 13.1 & 13.3 & 11.3 & - & 13.2 & 12.7 & - \\
\hline CDC stage C (\%) & 22.6 & 25.4 & 0 & $<0.001$ & 20.2 & 41.3 & $<0.001$ \\
\hline Median CD4 (/mm³) & 248 & 230 & 513 & $<0.001$ & 256 & 182 & $<0.001$ \\
\hline Median HIV-RNA (log cps/mL) & 4.8 & 4.8 & 4.4 & $<0.001$ & 4.7 & 4.9 & $<0.001$ \\
\hline HIV-RNA > $10^{5}$ copies/mL (\%) & 40.5 & 41.4 & 14.3 & $<0.0001$ & 37.3 & 48.2 & $<0.0001$ \\
\hline
\end{tabular}

Abbreviations: MSM men who have sex with men, $H B V$ hepatitis B virus, $H C V$ hepatitis $C$ virus, CDC Centers for Disease Control and Prevention, HIV human immunodeficiency virus. 
Table 3 Twelve months outcomes after cART initiation according to treatments that did/did not follow the guidelines

\begin{tabular}{|c|c|c|c|c|c|c|c|}
\hline \multirow[b]{2}{*}{ Characteristic } & \multirow{2}{*}{$\begin{array}{l}\text { All population } \\
\mathrm{N}=1,365\end{array}$} & \multicolumn{3}{|c|}{ "When-to-start" guidelines } & \multicolumn{3}{|c|}{ "What-to-start" guidelines } \\
\hline & & $\begin{array}{l}\text { Followed guidelines } \\
(n=1,214)\end{array}$ & $\begin{array}{l}\text { Outside of guidelines } \\
(n=151)\end{array}$ & P & $\begin{array}{l}\text { Followed guidelines } \\
(n=1,215)\end{array}$ & $\begin{array}{l}\text { Outside of guidelines } \\
(n=150)\end{array}$ & $P$ \\
\hline CART modification (\%) & 43.6 & 43.7 & 43.4 & - & 41.2 & 62.7 & $<0.001$ \\
\hline \multirow{2}{*}{$\begin{array}{l}12 \text { months CD4 }\left(/ \mathrm{mm}^{3}\right) \\
\text { (median }[\mathrm{IQR}])\end{array}$} & 395 & 369 & 619 & $<0.001$ & 406 & 313 & $<0.001$ \\
\hline & [241-538] & [224-506] & [504-766] & & {$[257-548]$} & [148-484] & \\
\hline \multirow{2}{*}{$\begin{array}{l}\text { CD4 gain }\left(/ \mathrm{mm}^{3} \text { ) }\right. \\
\text { (median [IQR]) }\end{array}$} & 137 & 139 & 89 & 0.006 & 144 & 69 & $<0.001$ \\
\hline & [33-238] & [39-239] & {$[0-216]$} & & [40-239] & {$[0-204]$} & \\
\hline \multirow{2}{*}{$\begin{array}{l}12 \text { months HIV-RNA (log } \\
\text { copies/mL) (median [IQR]) }\end{array}$} & 1.7 & 1.7 & 1.7 & - & 1.7 & 1.9 & $<0.001$ \\
\hline & {$[1.6-2.3]$} & {$[1.6-2.3]$} & {$[1.7-2.4]$} & & {$[1.6-2.2]$} & {$[1.7-3.4]$} & \\
\hline HIV-RNA <50 copies/mL (\%) & 64.6 & 64.3 & 66.9 & - & 66.8 & 47.3 & $<0.001$ \\
\hline Deceased (\%) & 0.8 & 0.9 & 0 & - & 0.6 & 2.7 & 0.007 \\
\hline
\end{tabular}

Abbreviations: IQR interquartile range, CART combined antiretroviral therapy, HIV human immunodeficiency virus.

start" guidelines was associated with a higher treatment modification rate $(\mathrm{cOR}=2.39,95 \% \mathrm{CI} 1.69-3.94, P<.001)$, decreased rate of HIV-RNA $<50$ copies $/ \mathrm{mL}(\mathrm{cOR}=0.45$, 95\% CI 0.32-0.63, $P<.001)$, and decreased CD4 count at 12 months $(\mathrm{cRC}=-36.0,95 \% \mathrm{CI}-63.0 ;-9.0, P=.009)$.

Factors independently associated with cART modification during the first year of treatment were female gender, CDC stage $C$, year of guideline publication (with a tendency toward less treatment modification over time), and a treatment that did not follow the "what-to-start" guidelines. A sensitivity analysis was performed by excluding simplification of treatment from other causes of cART modification. This analysis gave similar results (data not shown).

Factors independently associated with a greater increase in CD4 counts at 12 months were CDC stage A$\mathrm{B}$, baseline HIV-RNA < 105 copies/mL, absence of HBV/ $\mathrm{HCV}$ coinfection, pursuit of the same cART during the first year, and initiation of cART after 2004. Treatments that followed the "what-to-start" guidelines were not independently associated with CD4 count variation at 12 months.

Factors independently associated with an undetectable HIV-RNA at 12 months were CDC stage A-B, pursuit of the same cART during the first year, initiation of cART after 2006, and treatments following the "what-to-start" guidelines.

Treatments that followed the "when-to-start" guidelines were not independently associated with cART modification, CD4 increase, or undetectable HIV-RNA at 12 months. The results of these different models are summarized in Table 4.

\section{Discussion}

The objective of this study was to identify the relationship in daily practice between following treatment guidelines and the outcome within 1 year of initiating
cART. Following the guidelines appeared overall satisfactory in this well-defined population of cART-naïve HIV-infected adults. However, $11 \%$ of patients were treated outside of the "when-to-start" guidelines and 11\% outside of the "what-to-start" guidelines. Similar results have been observed in other European and Australian studies [9,12-14]. A higher rate of treatments initiated outside the guidelines was reported in 2 studies from the United States (not following the "what-to-start" guidelines in $46 \%$, not following the "what-to-start" guidelines in 21$56 \%)[10,11]$, but one of these studies included patients treated prior to the cART era in 1996, which could explain such differences.

The reasons for initiating treatment outside the guidelines appeared remarkably different when considering whether or not the "when-to-start" or "what-to-start" guidelines were followed. Patients initiating cART outside the "when-to-start" guidelines were typically young men having sex with men, less immunocompromised than the other patients, who initiate cART at a higher CD4 count level than those recommended at that time. Since the recommended CD4 count threshold has increased over time, patients starting cART above this threshold generally anticipated the following guidelines. Initiating treatment above the given CD4 count threshold was also observed in Danish and Australian studies $[13,15]$, with a similar tendency for the rate to decline over time in the former study. As a consequence of the evolution of guidelines, the practice of not following the "when-to-start" guidelines declined over time and should be minimal in the future since the recently published French guidelines, like the American guidelines [23], now recommend initiating cART in every patient irrespective of CD4 count [7].

The 1-year outcomes were quite similar whether or not the "when-to-start" guidelines were followed. Not surprisingly, patients initiating treatment outside these 
Table 4 Factors associated with 12-month outcomes following cART initiation

\begin{tabular}{|c|c|c|c|c|c|c|}
\hline \multirow[b]{2}{*}{ Characteristic } & \multicolumn{2}{|c|}{ cART modification before 12 month } & \multicolumn{2}{|c|}{ HIV-RNA $<50$ copies $/ \mathrm{mL}$ at 12 month } & \multicolumn{2}{|c|}{ CD4 variation from baseline } \\
\hline & $\mathrm{aOR}^{*}$ & $P$ & $\mathrm{aOR}^{*}$ & $P$ & $a R C^{*}$ & $P$ \\
\hline CART modification & ** & ** & $0.19(0.15-0.24)$ & $<.001$ & $-68.2(-84.5 ;-52.0)$ & $<.001$ \\
\hline Outside "what-to-start" guidelines & $1.90(1.45-2.49)$ & $<.001$ & $0.67(0.45-1.00)$ & .05 & - & - \\
\hline \multicolumn{7}{|l|}{ Year of guidelines (ref: 2000) } \\
\hline 2002 & $0.63(0.42-0.97)$ & .03 & $0.96(0.60-1.53)$ & - & $4.4(-26.2-34.9)$ & - \\
\hline 2004 & $0.57(0.37-0.87)$ & .009 & $1.44(0.90-2.31)$ & - & $(14.0-75.5)$ & .004 \\
\hline 2006 & $0.33(0.22-0.58)$ & $<.001$ & $2.07(1.31-3.28)$ & .002 & $51.4(22.2-80.6)$ & .001 \\
\hline 2008 & $0.40(0.27-0.58)$ & $<.001$ & $2.05(1.32-3.17)$ & .001 & $35.9(7.7-64.0)$ & .01 \\
\hline 2010 & $0.40(0.26-0.62)$ & $<.001$ & $1.95(1.19-3.20)$ & .008 & $27.6(-3.9-59.1)$ & - \\
\hline Male gender & $0.76(0.59-0.96)$ & .02 & - & - & - & - \\
\hline HBV/HCV coinfection & - & - & - & - & $-26.1(-49.6 ;-2.6)$ & .03 \\
\hline CDC stage $C$ & $1.90(1.45-2.49)$ & $<.001$ & $0.54(0.40-0.73)$ & $<.001$ & $-39.4(-60.5 ;-18.3)$ & $<.001$ \\
\hline HIV-RNA $>10^{5} \mathrm{cps} / \mathrm{mL}$ & - & - & $* *$ & $* *$ & $61.0(44.3-77.7)$ & $<.001$ \\
\hline
\end{tabular}

Abbreviations: $H B V$ hepatitis B virus, HCV hepatitis C virus, CDC Centers for Disease Control and Prevention, HIV human immunodeficiency virus, aOR adjusted odds ratio, $a R C$ adjusted regression coefficient.

Variables not retained in the final multivariate models: age, HIV risk factor, baseline CD4, delay from HIV diagnosis to cART initiation, adherence to "when-to-start" guidelines.

*Adjusted on the other covariates.

${ }^{* *}$ Covariate not in the model.

guidelines had higher 12 month CD4 counts but lower CD4 increases than other patients. The virological efficacy was, however, identical between groups, and there was a similar rate of treatment modification during the first year of treatment. Therefore, neither a beneficial nor a detrimental evolution was observed after 1 year of follow-up in patients initiating treatment outside the "when-to-start" guidelines, whereas long-term differences could not be ruled-out in this study. Additionally, initiating cART earlier in these patients could have been associated with other benefits not measured in this study, such as a reduction in infectiosity and contagiousness.

Following the "when-to-start" guidelines was better during the studied period than during the pre-cART $(<1996)$ and early-cART eras (1996-1999), when the rapid evolution of knowledge led physicians to largely anticipate the guidelines [24]. Similar to "when-to-start" guidelines, prescribing treatments outside of the "whatto-start" guidelines declined over time, whilst the reasons for initiating cART outside of these guidelines appeared to be different. Patients who initiated treatment outside these guidelines appeared to be more immunocompromised than others, whereas demographic factors were not as discriminant. Despite the fact that HBV/ $\mathrm{HCV}$ coinfections may require specific considerations for cART, this characteristic was not associated with use of non-recommended treatments. Reasons for initiating cART that were outside of the "what-to-start" guidelines differ markedly in the literature. Intravenous drug usage
[13], female gender [14], a higher education level [14], age younger than 60 years [10], white race [10], city or state of treatment $[10,15]$, year of treatment $[10,11,14,15]$, lowest $[10]$ or highest $[10,14] \mathrm{CD} 4$ count, and lowest $[10,11,14]$ or highest $[10,12,14]$ HIV viral load have all been reported as associated with a non-recommended treatment, precluding the identification of a unique pattern.

Twelve-month outcomes were remarkably different regarding whether or not "what-to-start" guidelines were followed. Patients initiating cART outside of these guidelines had significantly worse immunological and virological outcomes and more treatment modifications during the first year than patients treated within these guidelines. A similar result was observed in the Swiss Cohort [14] in which an HIV viral load $<400$ copies/mL at 1 year was significantly less frequent when cART was initiated outside the IAS-USA guidelines. However, this result was no longer significant when considering a $<50$ copies $/ \mathrm{mL}$ threshold, and there was no difference in CD4 count increases, unlike in our study. Differences in demographic characteristics may explain such differences, since patients in the Swiss Cohort were slightly younger, more frequently intravenous drug users, and more frequently coinfected with $\mathrm{HCV}$ than our patients. Similarly, more patients initiated cART with CD4 counts below $200 / \mathrm{mm}^{3}$ in this study, whereas more patients initiated cART with CD4 counts between 200 and $350 / \mathrm{mm}^{3}$ in our study. However, the distribution of HIV viral load at initiation of treatment was similar between the 2 cohorts. 
Treatments outside of the "when-to-start" guidelines were not associated with virological or immunological outcome at 12 months. Conversely, complex interactions were observed between treatment modifications during the first year, immunological and virological response at 1 year, and following the "what-to-start" guidelines. CDC stage $\mathrm{C}$ and the year of guideline publication were common predictors of all 12-month outcomes. Similarly, cART modification was negatively associated with an undetectable HIV-RNA at 12 months and with CD4 count increases from baseline. Female gender was associated with more treatment modifications during the first year, but was not associated with immunological and virological response. As previously reported [25,26], $\mathrm{HBV} / \mathrm{HCV}$ coinfection was associated with lower CD4 count increases from baseline, but was not associated with more treatment modifications or worse virological response. Higher HIV viral load was associated with a greater CD4 count increase, which has also been previously reported $[14,27]$. Finally, not following the "whatto-start" guidelines was independently associated with a worse virological response. Contrary to the Swiss Cohort study [14], age, HIV risk factors, and baseline CD4 counts were not associated with 12-month outcomes. Differences in populations and the selection of variables can explain such discrepancies between the study results. However, our study is the first to report a clear association between following the "what-to-start" guidelines and the virological response at 1 year using the universally accepted cut-off of $<50$ copies $/ \mathrm{mL}$, irrespective of the degree of immunodeficiency.

Limitations of this study include the follow-up that was voluntarily limited to 1 year in order to assess the effect of the first line of cART. Data on adherence and compliance were not collected, as well as associated comorbidities, which could have influenced the timing of cART initiation or the choice of drugs. A center effect could not be excluded, but the monocentric nature of the study allowed us to better characterize the predictors of outcome, since the study was less susceptible to heterogeneity in patient care than multicentric ones. Since the French guidelines for treating HIV infection are widely recognized in France, we referred to these guidelines rather than those of the IAS-USA or other international organizations, but we speculate that given the convergence of these guidelines over time, our conclusions would have been the same using a different set of guidelines. Excluding acute infection from the study could be another possible limitation since many physicians have been treating acute infection far before guidelines indicated to do so. However, since recommendations on the treatment of primary infection evolved with time, excluding acute infections provided homogeneity in our study population.

\section{Conclusions}

In conclusion, initiating treatments that did not follow the "when-to-start" guidelines was related to cART initiation at higher $\mathrm{CD} 4$ counts than the recommended level at the time, mainly in young men who have sex with men, and was not associated with a significantly different 12-month outcome than observed in the same population during that period of time. Conversely, not following the "what-to-start" guidelines was not observed in any specific population and led to significantly worse virological outcomes at 12 months and more treatment modifications during the first year of cART. Efforts should be made to promote adherence to the "what-tostart" guidelines and to assess the adequacy of prescriptions within these guidelines.

\section{Abbreviations}

aOR: Adjusted odds ratio; aRC: Adjusted regression coefficient; CDC: Centers for disease control and prevention; CART: Combined antiretroviral therapy; HBV: Hepatitis B virus; HCV: Hepatitis C virus; HIV: Human immunodeficiency virus; IQR: Interquartile range; NRTI: Nucleoside/nucleotide reverse transcriptase inhibitor.

\section{Competing interests}

Laurent Cotte has participated to a board for Mylan, has received research grants from ViiV and MSD and has received travel expenses from Abbott, Boehringer, BMS, Gilead, Janssen, MSD, Roche and ViiV. Philippe Vanhems has received research grants from Sanofi Pasteur. Thomas Bénet, Corinne Brochier, Thomas Perpoint, Tristan Ferry and Christian Chidiac declared that they have no competing interests.

\section{Authors' contribution}

LC designed the study, collected the data, participated to data analysis and interpretation, drafted and revised the article. TB analyzed the data,

participated to data interpretation and revised the article. PV designed the study, analyzed the data participated to data interpretation and revised the article. CB collected the data, participated to data interpretation and revised the article. TP collected the data, participated to data interpretation and revised the article. TF collected the data, participated to data interpretation and revised the article. CC designed the study, collected the data, participated to data analysis and interpretation and revised the article. All authors read and approved the final manuscript.

\section{Acknowledgment}

The authors thank all the patients who participated to this study and the physicians taking care for them.

\section{Author details}

'Department of Infectious and Tropical Diseases, Hôpital de la Croix-Rousse, Hospices Civils de Lyon, Lyon, France. ${ }^{2}$ INSERM, U1052, Lyon, France. ${ }^{3}$ Infection Control and Epidemiology Unit, Edouard Herriot Hospital, Hospices Civils de Lyon, Lyon, France. ${ }^{4}$ University Claude Bernard - Lyon-1, UMR CNRS 5558, Lyon, France. ${ }^{5} \mathrm{Clinical}$ Research Unit, Hôpital de la Croix-Rousse, Hospices Civils de Lyon, Lyon, France. ${ }^{6}$ University Claude Bernard - Lyon-1, Lyon, France. ${ }^{7} \mathrm{CIRI}$, INSERM U1111, Lyon, France.

Received: 24 April 2014 Accepted: 29 October 2014

Published online: 14 November 2014

\section{References}

1. Lewden C, Bouteloup V, De Wit S, Sabin C, Mocroft A, Wasmuth JC, van Sighem A, Kirk O, Obel N, Panos G, Ghosn J, Dabis F, Mary-Krause M, Leport C, Perez-Hoyos S, Sobrino-Vegas P, Stephan C, Castagna A, Antinori A, d'Arminio Monforte A, Torti C, Mussini C, Isern V, Calmy A, Teira R, Egger M, Grarup J, Chene G: All-cause mortality in treated HIV-infected adults with CD4 5500/ $\mathrm{mm}^{3}$ compared with the general population: evidence from a 
large European observational cohort collaboration. Int J Epidemio/ 2012, 41:433-445.

2. May MT, Gompels M, Delpech V, Porter K, Orkin C, Kegg S, Hay P, Johnson M, Palfreeman A, Gilson R, Chadwick D, Martin F, Hill T, Walsh J, Post F, Fisher M, Ainsworth J, Jose S, Leen C, Nelson M, Anderson J, Sabin C: Impact on life expectancy of HIV-1 positive individuals of CD4R cell count and viral load response to antiretroviral therapy. AIDS 2014, 28:1193-1202.

3. Nakagawa F, Lodwick RK, Smith CJ, Smith R, Cambiano V, Lundgren J, Delpech V, Phillips AN: Projected life expectancy of people with HIV according to timing of diagnosis. AIDS 2012, 26(3):335-343.

4. Thompson MA, Aberg JA, Hoy JF, Telenti A, Benson C, Cahn P, Eron JJ Jr, Gunthard HF, Hammer SM, Reiss P, Richman DD, Rizzardini G, Thomas DL, Jacobsen DM, Volberding PA: Antiretroviral treatment of adult HIV infection: 2012 recommendations of the International Antiviral Society-USA panel. JAMA 2012, 308(4):387-402.

5. Williams I, Churchill D, Anderson J, Boffito M, Bower M, Cairns G, Cwynarski K, Edwards S, Fidler S, Fisher M, Freedman A, Geretti AM, Gilleece Y, Horne R, Johnson M, Khoo S, Leen C, Marshall N, Nelson M, Orkin C, Paton N, Phillips A, Post F, Pozniak A, Sabin C, Trevelion R, Ustianowski A, Walsh J, Waters $L$, Wilkins $E$, et al: British HIV association guidelines for the treatment of HIV-1-positive adults with antiretroviral therapy 2012. HIV Med 2012, 13(Suppl 2):1-85.

6. European AIDS Society: European AIDS Society Guidelines- Version 7.0 - October 2013.. http://www.eacsociety.org/Portals/0/ Guidelines_Online_131014.pdf. Accessed November 14, 2014.

7. Morlat P: Prise en charge médicale des personnes vivants avec le VIH. Recommandations du groupe d'experts. Paris: La documentation française; 2013. http://www.sante.gouv.fr/rapport-2013-sur-la-prise-encharge-medicale-des-personnes-vivant-avec-le-vih.html. Accessed November 14, 2014.

8. Keiser O, Orrell C, Egger M, Wood R, Brinkhof MW, Furrer H, van Cutsem G, Ledergerber B, Boulle A, Swiss HIV Cohort Study (SHCS) and the International Epidemiologic Databases to Evaluate AIDS in Southern Africa (leDEA-SA): Public-health and individual approaches to antiretroviral therapy: township South Africa and Switzerland compared. PLoS Med 2008, 5(7):e148.

9. Brook MG, Curtis H, Johnson MA, British HIV: Association Clinical Audit Committee: findings from the British HIV Association's national clinical audit of first-line antiretroviral therapy and survey of treatment practice and maternity care, 2002. HIV Med 2004, 5(6):415-420.

10. Holodniy M, Hornberger J, Rapoport D, Robertus K, MaCurdy TE, Lopez J, Volberding P, Deyton L: Relationship between antiretroviral prescribing patterns and treatment guidelines in treatment-naive HIV-1-infected US veterans (1992-2004). J Acquir Immune Defic Syndr 2007, 44(1):20-29.

11. Cocohoba J, Wang QJ, Cox C, Gange SJ, Cohen M, Glesby M, De Hovitz JA, Greenblatt RM: Consistency of initial antiretroviral therapy with HIV treatment guidelines in a US cohort of HIV-infected women. J Acquir Immune Defic Syndr 2008, 47(3):377-383.

12. Suarez-Lozano I, Viciana P, Lacalle JR, Teira R, Lozano F, Lopez-Aldeguer J, Pedrol E, Domingo P, Cosin J, Roca B, Geijo P, Fuente B, Vergara A, Ribera E, Galindo MJ, Zapata A, Sanchez T, Vidal F, Munoz-Sanz A, Munoz-Sanchez J, Garrido M: The relationship between antiretroviral prescription patterns and treatment guidelines in treatment-naïve HIV-1-infected patients. HIV Med 2009, 10(9):573-579.

13. Petersen TS, Andersen SE, Gerstoft J, Thorsteinsson K, Larsen CS, Pedersen G, Pedersen C, Obel N: Adherence to national guidelines for initiation of antiretroviral regimens in HIV patients: a Danish nationwide study. Br J Clin Pharmacol 2011, 72(1):116-124.

14. Wandeler G, Keiser O, Hirschel B, Gunthard HF, Bernasconi E, Battegay M, Clerc O, Vernazza PL, Furrer H: Swiss HIV cohort study: a comparison of initial antiretroviral therapy in the Swiss HIV cohort study and the recommendations of the international AIDS society-USA. PLOS One 2011, 6(12):e27903.

15. Bloch M, Hoy J, Cunningham N, Roth N, Bailey M, Pierce A, Watson J, Carr A: Adherence to HIV treatment guidelines for comorbid disease assessment and initiation of antiretroviral therapy. J Acquir Immune Defic Syndr 2012, 59(5):478-488

16. Phillips AN, Grabar S, Tassie JM, Costagliola D, Lundgren JD, Egger M: Use of observational databases to evaluate the effectiveness of antiretroviral therapy for HIV infection: comparison of cohort studies with randomized trials. EuroSIDA, the French Hospital Database on HIV and the Swiss HIV Cohort Study Groups. AIDS 1999, 13:2075-2082.

17. Delfraissy JF: Prise en charge thérapeutique des personnes infectées par le VIH. Recommandations du groupe d'experts. Mise à jour 2000 du rapport 1999. Paris: Médecine-Sciences Flammarion; 2000.

18. Delfraissy JF: Prise en charge des personnes infectées par le VIH. Recommandations du groupe d'experts. Recommendations du groupe d'Experts. Paris: La documentation Française; 2002. http://www. ladocumentationfrancaise.fr/rapports-publics/034000460-prise-en-chargedes-personnes-infectees-par-le-vih-recommandations-du-groupe-d-experts. Accessed November 14, 2014.

19. Delfraissy JF: Prise en charge thérapeutique des personnes infectées par le VIH. Recommandations du groupe d'experts. Recommendations du groupe d'Experts. Paris: La documentation française; 2004. http://www. ladocumentationfrancaise.fr/rapports-publics/044000467-prise-en-chargetherapeutique-des-personnes-infectees-par-le-vih-rapport-2004. Accessed November 14, 2014.

20. Yeni P: Prise en charge médicale des personnes infectées par le VIH. Recommandations du groupe d'experts. Paris: La documentation française; 2006. http://www.sante.gouv.fr/IMG/pdf/rapport_experts_2006.pdf. Accessed November 14, 2014.

21. Yeni P: Prise en charge médicale des personnes infectées par le VIH. Recommandations du groupe d'experts. Paris: La documentation française; 2008. http://www.ladocumentationfrancaise.fr/var/storage/ rapports-publics/084000593/0000.pdf. Accessed November 14, 2014.

22. Yeni P: Prise en charge médicale des personnes infectées par le VIH. Recommandations du groupe d'experts. Paris: La documentation française; 2010. http://www.sante.gouv.fr/rapport-2010-sur-la-prise-encharge-medicale-des-personnes-infectees-par-le-vih-sous-la-direction-du-prpatrick-yeni.html. Accessed November 14, 2014.

23. HHS Panel on Antiretroviral Guidelines for Adults and Adolescents: Guidelines for the Use of Antiretroviral Agents in HIV-1-Infected Adults and Adolescents; 2014. http://aidsinfo.nih.gov/ContentFiles/ AdultandAdolescentGL.pdf. Accessed November 14, 2014.

24. Dhenain M, Vanhems P, Colin C, Peyramond D, Chidiac C, Touraine J L, Trépo C, Fabry J: Published guidelines have a limited impact on the first prescription of antiretroviral therapy for HIV-1-infected patients in Lyon, France. AIDS 2000, 14(11):1673-1674.

25. Greub $G$, Ledergerber $B$, Battegay $M$, Grob $P$, Perrin L, Furrer $H$, Burgisser $P$, Erb P, Boggian K, Piffaretti JC, Hirschel B, Janin P, Francioli P, Flepp M, Telenti A: Clinical progression, survival, and immune recovery during antiretroviral therapy in patients with HIV-1 and hepatitis $C$ virus coinfection: the Swiss HIV Cohort Study. Lancet 2000, 356(9244):1800-1805.

26. Lincoln D, Petoumenos K, Dore GJ, Australian HIV: Observational Database. $\mathrm{HIV} / \mathrm{HBV}$ and $\mathrm{HIV} / \mathrm{HCV}$ coinfection, and outcomes following highly active antiretroviral therapy. HIV Med 2003, 4(3):241-249.

27. Smith CJ, Sabin CA, Youle MS, Kinloch-de Loes S, Lampe FC, Madge $S$, Cropley I, Johnson MA, Phillips AN: Factors influencing increases in CD4 cell counts of HIV-positive persons receiving long-term highly active antiretroviral therapy. J Infect Dis 2004, 190(10):1860-1868.

\section{doi:10.1186/s12879-014-0596-y}

Cite this article as: Cotte et al:: The effect of adherence to guidelines for initial antiretroviral therapy on 1-year outcomes: a French cohort study. BMC Infectious Diseases 2014 14:596. 